\title{
Phytochemical Profile and Antioxidant and Antiproliferative Activity of Sedum dendroideum on Pterygium Fibroblasts
}

\author{
Paloma López-Montemayor $\mathbb{D}^{\mathbb{D}},{ }^{1}$ Judith Zavala ${ }^{\mathbb{D}},{ }^{1}$ María Dolores Montalvo-Parra ${ }^{\mathbb{D}}{ }^{1}$ \\ Guillermo Isaac Guerrero-Ramírez $\mathbb{D}^{1},{ }^{1}$ Karla Mayolo-Deloisa $\mathbb{D}{ }^{2}{ }^{2}$ \\ Daniela Enriquez-Ochoa $\mathbb{D},{ }^{2}$ Bernardo Martínez-García, ${ }^{1}$ Denise Loya-García $\mathbb{D}^{1}{ }^{1}$ \\ Alba Miriam Guerrero-Martínez $\mathbb{D}^{\mathbb{D}}{ }^{1}$ and Jorge Eugenio Valdez-García $\mathbb{D}^{1}$ \\ ${ }^{1}$ Tecnologico de Monterrey, Escuela de Medicina, 3000 Morones Prieto Ave, Col. Los Doctores, C. P. 64710, Monterrey, \\ Nuevo Leon, Mexico \\ ${ }^{2}$ Tecnologico de Monterrey, Escuela de Ingenieria y Ciencias, 2501 Eugenio Garza Sada Ave, Col. Tecnologico, C. P. 64849, \\ Monterrey, Nuevo Leon, Mexico
}

Correspondence should be addressed to Judith Zavala; judith.zavala@tec.mx

Received 26 May 2021; Revised 29 September 2021; Accepted 11 October 2021; Published 18 October 2021

Academic Editor: José Roberto Santin

Copyright (c) 2021 Paloma López-Montemayor et al. This is an open access article distributed under the Creative Commons Attribution License, which permits unrestricted use, distribution, and reproduction in any medium, provided the original work is properly cited.

\begin{abstract}
Background. Sedum dendroideum has antioxidant effects that are beneficial for different diseases. We aimed to analyze the antiproliferative activity of $S$. dendroideum in human pterygium fibroblasts (HPFs). Methods. HPFs were treated for $24 \mathrm{~h}$ with $0-1000 \mu \mathrm{g} / \mathrm{mL}$ of $S$. dendroideum lyophilized to analyze its effect on cell viability using the CellTiter assay. RNA from HPF treated with $250 \mu \mathrm{g} / \mathrm{mL}$ of $S$. dendroideum lyophilized was isolated, and the expression of VEGF and CTGF genes was evaluated by qPCR. A dermal fibroblast cell line (HDFa) was used as a healthy control. The total phenolic content, antioxidant activity, and chemical profile of $S$. dendroideum lyophilized were determined. Results. Viability of HPF decreased after $24 \mathrm{~h}$ treatment of $S$. dendroideum in a dose-dependent manner. The expression of VEGF and CTGF significantly decreased $(P<0.01)$ in HPF treated with $250 \mu \mathrm{g} /$ $\mathrm{mL}$ of $S$. dendroideum when compared with untreated HPF. The total phenolic concentration in the $S$. dendroideum lyophilized was $33.67 \mathrm{mg}$ gallic acid equivalents (GAE)/g. Antioxidant activity was $384.49 \mathrm{mM}$ Trolox equivalents/mL. The main phenolic compounds identified by HPLC analysis were the kaempferol-3-O-glycoside, kaempferol-3-O-rhamnoside, kaempferol-3-Oneohesperidoside-7-O- $\alpha$-rhamnopyranoside, and kaempferol-3-O-glycoside-7-O-rhamnoside. Conclusions. S. dendroideum decreases the proliferation of HPF and the expression of VEGF and CTGF. The phenolic compound concentration, antioxidant activity, and phytochemical profile may play a role in these effects.
\end{abstract}

\section{Introduction}

Succulent plants, or Sempervivum, are part of the Crassulaceae family and are well known for their medicinal properties. The Sedum genre has more than 30 species. $S$. dendroideum is a species commonly used in Brazilian and Mexican traditional medicine due to its analgesic, antimicrobial, and gastroprotective properties. Previous scientific reports proved its activity against pain (antinociceptive) in an induced peritonitis model, antioxidant activity used as a fresh leaf infusion, antiglycemic effect in diabetic mice, anti- inflammatory activity in vitro due to its ability to stimulate macrophages to produce cytokines, and gastroprotective effect in vivo [1-4]. These properties are related to vegetal secondary metabolites, including flavonoids glycosides, tannins, kaempferol, quercetin, and phenols. Given the potential of $S$. dendroideum, we aimed to analyze it for a common ocular disease for which there is no pharmacological treatment. Pterygium is a wing-shaped tissue growth over the conjunctiva. It produces ocular irritation, foreign body sensation, and prurience, and its growth can interfere with the visual field [5]. It has tumor-like characteristics such 
as growth, migration, inflammation, and neovascularization. However, it is considered a benign growth because it does not metastasize. Pterygium prevalence is up to $\sim 10 \%$ within the population of areas at a high risk considering the mean annual UV index, such as regions near the equator [6]. The only treatment available is surgical removal, with a variable recurrence rate [7]. Pterygium pathogenesis is not fully understood; however, long-term sun ultraviolet-B (UV-B) radiation exposure and environmental pollution are welldocumented risk factors. This leads to dysregulation of molecules such as interleukins 1, 6, and 8; the growth factors VEGF, PDGF, bFGF, and CTGF; and metalloproteinases involved with the processes of inflammation, cell migration, proliferation, oxidative stress, and neovascularization [8, 9]. These cellular processes could be mitigated by the proven activity of $S$. dendroideum. Dysregulation of these molecular processes has been reported for both cell types of pterygium, epithelium, and fibroblasts.

Given the molecular properties proven of $S$. dendroideum, we aimed to analyze its effect on human pterygium fibroblasts by means of proliferation along with the chemical profile of possible active compounds. Thus, this provides evidence for the development of a potential pharmacological treatment for pterygium.

\section{Materials and Methods}

2.1. Plant Materials and Sap Extraction. The S. dendroideum plant was collected from a vivarium in Santiago, Nuevo Leon, Mexico. The stems and leaves $(176.04 \mathrm{~g})$ were blended with $100 \mathrm{~mL}$ of distilled $\mathrm{H}_{2} \mathrm{O}$, filtrated, and frozen at $-80^{\circ} \mathrm{C}$ for $24 \mathrm{~h}$. The solution was lyophilized for 6 days with a yield of $3.979 \mathrm{~g}$. A stock solution of $100 \mathrm{mg}$ of lyophilized powder in $1 \mathrm{~mL}$ of DMSO (Sigma-Aldrich, Missouri, USA) was prepared, filtered with a $0.22 \mu \mathrm{M}$ filter (Corning, New York, USA), and stored at $-20^{\circ} \mathrm{C}$.

2.2. Human Pterygium Fibroblast Primary Culture. The study was conducted in accordance with the Declaration of Helsinki. Four surgically removed pterygiums were donated by Hospital La Carlota, Montemorelos, NL. A small fraction (3 mm approximately) of each pterygium was fragmented and cultured with DMEM-F12 (Gibco, New York, USA) supplemented with $5 \% \mathrm{SBF}$ and $1 \%$ antibiotic at $37^{\circ} \mathrm{C}$ in a humidified chamber with $5 \% \quad \mathrm{CO}_{2}$. The medium was changed every third day upon confluence. Tissue fragments were removed from culture plates before the first passage. All cells were used from passage 3 to 10 for experimentation. As healthy control, a cell line (ATCC ${ }^{\circledR}$ PCS-201-012) of human dermal fibroblast (HDFa) was used.

2.3. Characterization of Pterygium Fibroblasts. To characterize the pterygium fibroblasts isolated from primary culture, the expression of keratin, Aldh3, and $\operatorname{Prdx} 2$ was analyzed by immunofluorescence. HPFs were fixed using $4 \%$ paraformaldehyde and stained for Aldh3a1 (1:100), Prdx2 $(1: 500)$, and pan-keratin $(1: 10)$ (Abcam, Cambridge, MA).
Images were taken with a structured illumination microscope (Zeiss ApoTome-DZNE W1).

2.4. Cell Viability Assay. Dilutions of the lyophilized stock solution were prepared using DMEM-F12 sterilized media. HFDa and HPF were treated with 0, 250, 500, 1000, and $1500 \mu \mathrm{g} / \mathrm{mL}$ of $S$. dendroideum for $24 \mathrm{~h}$. Each dose was tested in triplicate. Cell viability was analyzed with the CellTiterBlue Cell Viability Assay (Promega, Wisconsin, USA) according to the instructions provided by the manufacturer. In brief, cells were plated in 96-well culture plates at a density of 5000 cells per well in $200 \mu \mathrm{L}$ of medium and incubated overnight. The medium was replaced with medium $(200 \mu \mathrm{L} /$ well) containing different concentrations of $S$. dendroideum. After $24 \mathrm{~h}$, the medium was replaced with medium supplemented with the CellTiter-Blue reagent. After incubation for $1 \mathrm{~h}$, the fluorescence of the medium was measured using the Synergy HT Multi-Detection Microplate Reader. Pilot experiments indicated that seeding 5000 cells/well and incubating the cells with CellTiter-Blue reagent for $1 \mathrm{~h}$ after $S$. dendroideum treatment were optimal conditions.

2.5. VEGF and CTGF Expression Analysis. To evaluate the effect of $S$. dendroideum sap over the expression of CTGF and VEGF, a concentration of $250 \mu \mathrm{g} / \mathrm{mL}$ was used. This concentration was obtained as the half-maximal inhibitory concentration (IC50) in preliminary analysis (data not shown). Total RNA of HFDa and HPF treated with $250 \mu \mathrm{g} /$ $\mathrm{mL}$ of $S$. dendroideum sap and from untreated HPF was isolated using Trizol reagent according to the manufacturer's instructions (Merck, Darmstadt, Germany). cDNA was generated from RNA using the High-Capacity cDNA Reverse Transcription Kit (Applied Biosystems, California, USA). Each reaction contained $2 \mu \mathrm{L}$ of buffer $10 \mathrm{X}, 0.8 \mu \mathrm{L}$ of dNTPs, $2 \mu \mathrm{L}$ of random primers, $1 \mu \mathrm{L}$ of RT enzyme, and $4.2 \mu \mathrm{L}$ of nuclease-free water. The thermal cycler was run using the following program: primer annealing for $10 \mathrm{~min}$ at $25^{\circ} \mathrm{C}$, reverse transcription for $120 \mathrm{~min}$ at $37^{\circ} \mathrm{C}$, and enzyme deactivation for $5 \mathrm{~min}$ at $85^{\circ} \mathrm{C}$. The $\mathrm{qPCR}$ was carried out using PowerUp Green Master Mix (Applied Biosystems). Each sample contained $10 \mu \mathrm{L}$ of SYBR Green, $7.4 \mu \mathrm{L}$ of nuclease-free water, $0.6 \mu \mathrm{L}$ of primer, and $2 \mu \mathrm{L}$ of cDNA. Primer sequences used (Integrated DNA Technologies) are shown in Table 1 . To calculate the level of mRNA relative expression, values were analyzed using $\Delta \Delta \mathrm{Ct}$ using GAPDH as the endogenous gene.

2.6. S. dendroideum Phenolic Concentration Analysis. The total phenolic content was determined by means of spectrophotometric analysis with the Folin-Ciocalteu method. The concentration of polyphenols was quantified through a calibration curve of gallic acid equivalents $(\mathrm{mg} / \mathrm{mL})$. Folin-Ciocalteu reactive (Sigma-Aldrich) was used to analyze the dilutions of $S$. dendroideum samples. The results were expressed as gallic acid equivalents (mgGAE/mg dry lyophilized). This analysis was performed in triplicate. 
TABle 1: Primer sequences for different genes. The sequences are listed in the $5^{\prime}-3^{\prime}$ direction.

\begin{tabular}{lcc}
\hline Gene & F_Primer & R_Primer \\
\hline VEGF & TGGTTCCCGAAACGCTGAG & TGCCCACTGAGGAGTCCAAC \\
CTGF & GAAGGGCAAAAAGTGCATCC & GAAGGGCAAAAAGTGCATCC \\
GAPDH & GAGTCAACGGATTTGGTCGT & TTGATTTTGGAGGGATCTCG \\
\hline
\end{tabular}

2.7. S. dendroideum Antioxidant Activity. An oxygen radical absorbance capacity (ORAC) assay in 96-well multidetection plates was determined. Fluorescence sodium (Sigma, St. Louis, MO, USA) was used as a fluorescence probe, Trolox as a standard free radical scavenger, and AAPH as the peroxyl radical generator.

For 1 hour, the fluorescence was measured in a Synergy HT Multi-Detection Microplate Reader at $37^{\circ} \mathrm{C}$ with excitation/emission at 485/528 $\mathrm{nm}$ every 2 minutes.

2.8. HPLC Phenolic Compounds Analysis. The phenolic compound profile of $S$. dendroideum extract was evaluated on a 1260 Infinity HPLC system coupled to a diode array detector (DAD) (Agilent Technologies, CA, USA). The HPLC method followed has been reported previously [10]. In brief, the analysis was developed using a $5 \mu \mathrm{m}$ Luna C18 reverse-phase column (Phenomenex, CA, USA), maintained at $25^{\circ} \mathrm{C}$. The mobile phase consisted of water (eluent $\mathrm{A}$ ) and methanol-water $(60: 40 \% \mathrm{v} / \mathrm{v}$, eluent $\mathrm{B})$. The $\mathrm{pH}$ of both eluents was adjusted to 2.4 using phosphoric acid (D. E. Q., Monterrey, NL, Mexico). The gradient used was as follows: $0 \mathrm{~min}, 100 / 0$; $3 \mathrm{~min}, 70 / 30 ; 8 \mathrm{~min}, 50 / 50$; $35 \mathrm{~min}, 30 / 70$; $40 \mathrm{~min}, 20 / 80$; $45 \mathrm{~min}, 0 / 100 ; 50 \mathrm{~min}, 0 / 100$; and $60 \mathrm{~min}$, $100 / 0$ (time (\%) of eluent A/\% of eluent B). The method was run for $60 \mathrm{~min}$ at $0.8 \mathrm{~mL} / \mathrm{min}$ with a pressure of no more than 400 psi. The samples were prepared in DMSO ( Research Organics, Cleveland, OH, USA) and further diluted with water to a final concentration of $25 \mathrm{mg} / \mathrm{mL}$. Chromatograms were recorded at $360 \mathrm{~nm}$.

\section{Results}

3.1. The Influence of S. dendroideum on HPFs. Cultured HPFs expressed Aldh3, Prdx2, and pan-keratin (Figure 1) when analyzed by immunocytochemistry.

The reduction in cell viability after 24 hours of treatment was dose dependent. The IC50 was $208 \mu \mathrm{g} / \mathrm{mL}$. The viability of HFDa did not decrease with the treatment of S. dendroideum (Figure 2(a)).

The gene expression of VEGF and CTGF showed a significant decrease $(P<0.01)$ in HPF treated with $250 \mu \mathrm{g} /$ $\mathrm{mL}$ of $S$. dendroideum lyophilized sap compared with untreated cells. HFDa did not show a decrease in VEGF or CTGF expression after $S$. dendroideum lyophilized sap treatment (Figures 2(b) and 2(c)).

3.2. Characterization of $S$. dendroideum. The antioxidant activity of $S$. dendroideum analyzed by the AAPH method was $384.49 \mathrm{mM}$ Trolox equivalents/mL. The total polyphenol content of $S$. dendroideum dry lyophilizate was determined by the method of Folin-Ciocalteu assay, thus obtaining
$33.67 \mathrm{mg}$ gallic acid equivalents (GAE)/g. The HPLC profile of $S$. dendroideum showed several peaks corresponding to different phenolic compounds (Figure 3).

The retention time, maximum absorbance, and the percentage area of the main peaks are observed in Table 2 . To get a better insight into $S$. dendroideum chemical composition, the peaks were tentatively identified by comparing their UV spectrum and retention time with available data reported in the literature. The results suggest that the main phenolic compounds in $S$. dendroideum are kaempferol glycosides, such as kaempferol-3-O-glycoside, kaempferol3-O-rhamnoside, kaempferol-3-O-neohesperidoside-7-O$\alpha$-rhamnopyranoside, and kaempferol-3-O-glycoside-7-Orhamnoside.

\section{Discussion}

Pterygium is a disease with a high prevalence in regions near to the equator. It affects people whose activities involve chronic exposure to UV radiation. The only treatment available is surgical removal, which is not completely effective and may not be economically accessible to the main population affected. Several studies on S. dendroideum have found it to be beneficial in inflammatory and chronic diseases $[1,3,11]$. We aimed to analyze the activity of $S$. dendroideum over pterygium fibroblasts.

Pterygium fibroblasts have dysregulation in several molecular pathways related to antioxidant activity, migration, inflammation, and proliferation $[8,12]$. Some of these molecules are upregulated in pterygium samples, including ALDH3 and PRDX2. The former acts as a defense against $\mathrm{UV}$-induced oxidative stress on the ocular surface [13], while PRDX2 contributes as part of the antioxidant defense by inactivating hydrogen peroxide [14]. Specific forms of keratin, including keratin 13 and 4, are increased in pterygium and have a role in cell migration [15]. These three biomarkers were detected in the primary isolated HPF of this work.

HPFs treated with $S$. dendroideum lyophilized sap showed a dose-dependent viability decrease, while HFDa remained viable at all dosages. These results are in accordance with previous studies that demonstrated the antiproliferative effect of extracts from plants from the same family. A crude whole plant fraction from S. sarmentosum inhibits the growth of hepatocellular carcinoma and of a pancreatic cell line in a dose-dependent manner [16, 17]. For pterygium treatment, there are reports showing promising efficacy of plant-derived extracts. In a study conducted with 13 patients having pterygium or pinguecula treated with an herbal formulation, a $76.9 \%$ response improvement was registered [18]. The cited study did not describe how the improvement was assessed, and none of the herbal 


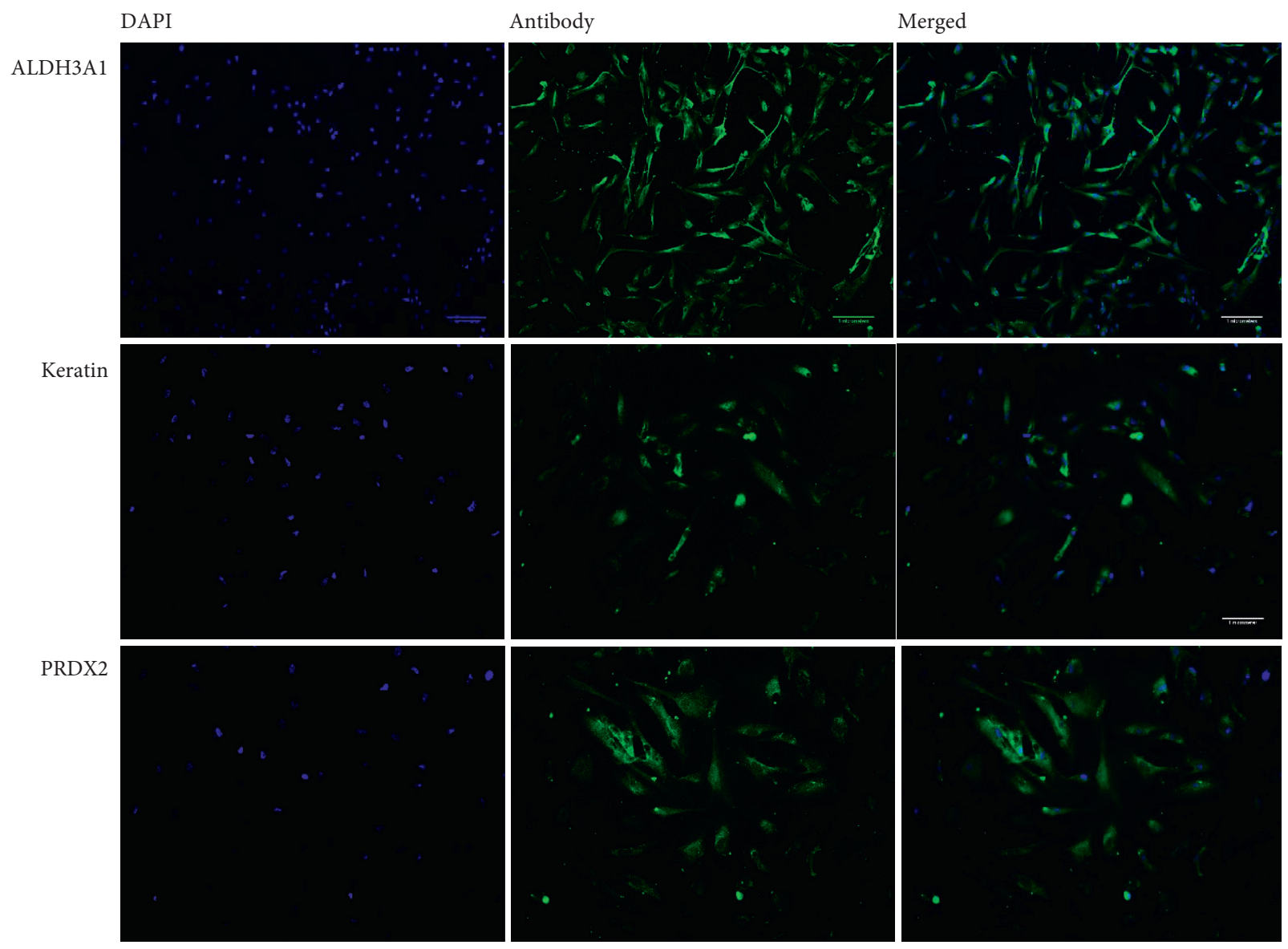

FIgURE 1: Immunodetection of Aldh3, keratin, and Prdx2 in primary isolated pterygium fibroblasts.

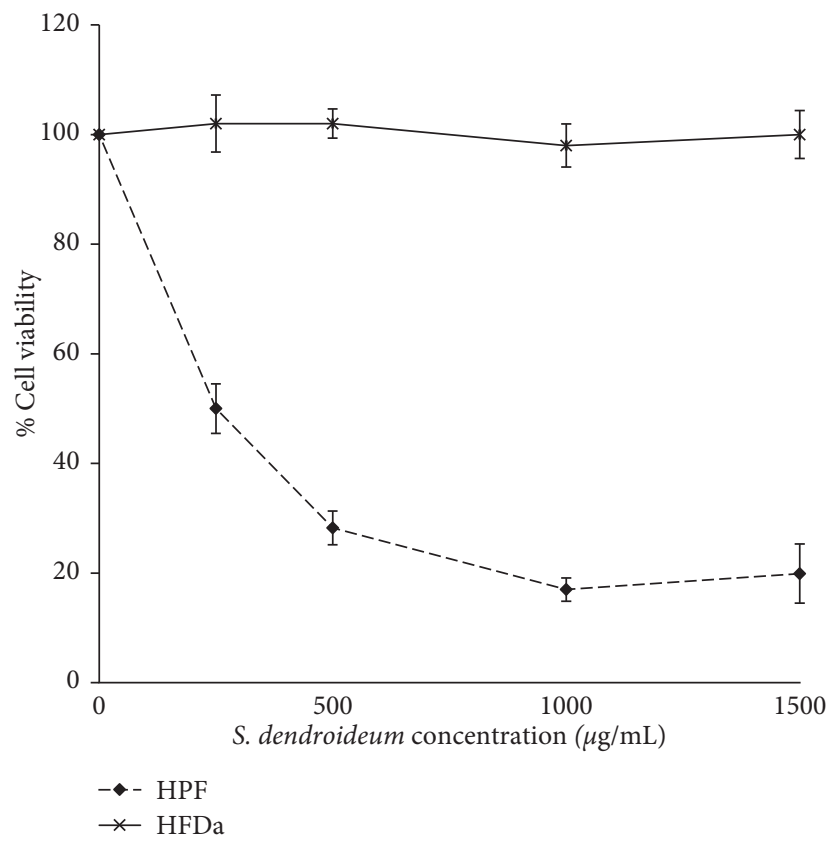

(a)

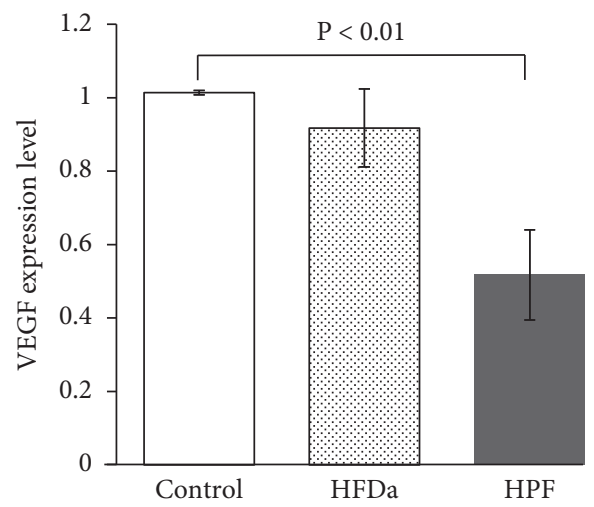

FIgURE 2: Continued.

(b) 


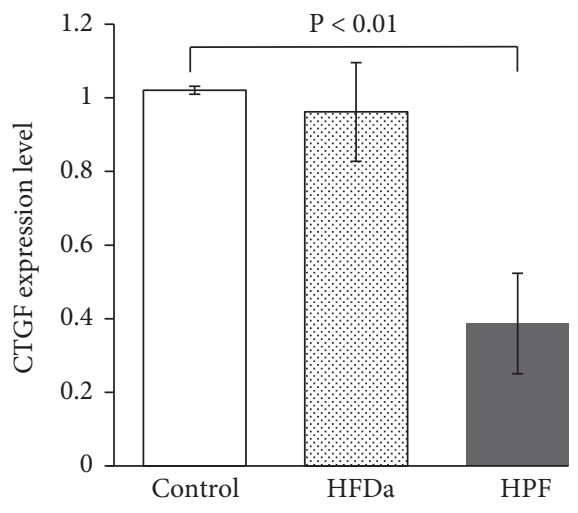

(c)

FIGURE 2: Cell viability changes of HPF and HFDa after treatment with $S$. dendroideum lyophilized (a). A significant decrease when analyzed with a $t$-test $(P<0.01)$ is registered in the expression of VEGF (b) and CTGF (c) in HPF treated with $250 \mu \mathrm{g} / \mathrm{mL}$ of $S$. dendroideum lyophilized compared with untreated cells (control).

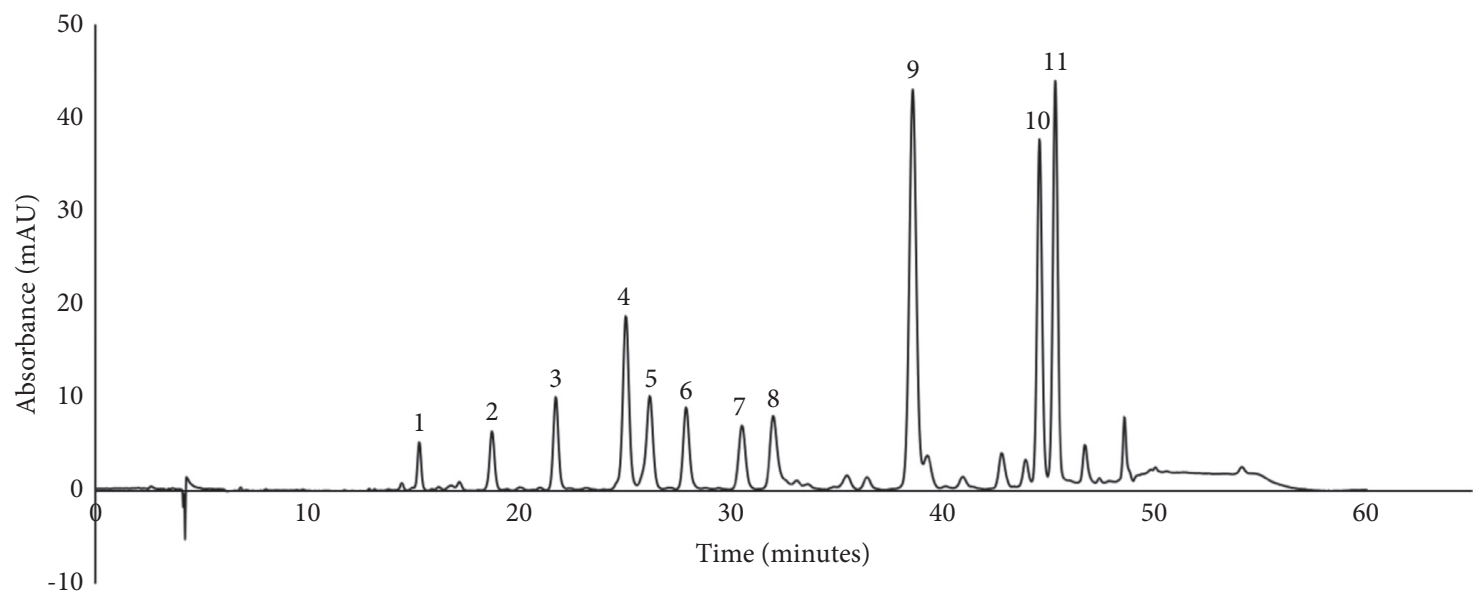

Figure 3: Phenolic compounds' profile in S. dendroideum obtained by HPLC-DAD at $360 \mathrm{~nm}$.

TABLE 2: Retention time $\left(t_{\mathrm{R}}\right)$, maximum absorption wavelengths $\left(\lambda_{\max }\right)$, and percentage area (\%) from the main peaks of phenolic compounds' profile obtained using HPLC-DAD at $360 \mathrm{~nm}$.

\begin{tabular}{|c|c|c|c|c|}
\hline Peak number & $t_{\mathrm{R}}$ (minutes) & $\lambda_{\max }(\mathrm{nm})$ & Tentative identification & $\%$ \\
\hline 1 & 15.283 & Not determined & Not identified & 1.4320 \\
\hline 2 & 18.708 & Not determined & Not identified & 2.4539 \\
\hline 3 & 21.719 & 272,334 & Apigenin-7-O-glycoside ${ }^{a}$ & 4.0420 \\
\hline 4 & 25.021 & 254 sh, 264, 296 sh, 316 sh, 354 & Kaempferol-3-O-glycoside ${ }^{a}$ & 8.9907 \\
\hline 5 & 26.154 & 246 sh, 268,318 sh, 348 & Kaempferol-3-O-glycoside-7-O-rhamnoside ${ }^{a}$ & 5.2386 \\
\hline 6 & 27.864 & $246 \mathrm{sh}, 266,318 \mathrm{sh}, 348$ & Kaempferol diglycoside $\mathrm{a}^{\mathrm{a}}$ & 4.2962 \\
\hline 7 & 30.504 & $246 \mathrm{sh}, 266,320 \mathrm{sh}, 348$ & Kaempferol diglycoside ${ }^{a}$ & 3.7200 \\
\hline 8 & 31.976 & Not determined & Not identified & 4.6247 \\
\hline 9 & 38.552 & 224 sh, 264,322 sh, 348 & Kaempferol glycoside ${ }^{\mathrm{b}}$ & 21.9344 \\
\hline 10 & 44.533 & $266,298 \mathrm{sh}, 356$ & Kaempferol-3-O-rhamnoside ${ }^{c}$ & 14.7406 \\
\hline 11 & 45.271 & $228 \mathrm{sh}, 264,314 \mathrm{sh}, 344$ & Kaempferol-3-O-neohesperidoside-7-O- $\alpha$-rhamnopyranoside ${ }^{\mathrm{d}}$ & 17.0646 \\
\hline
\end{tabular}

sh, shoulder. Identification based on the data reported by $[10]^{\mathrm{a}},[11]^{\mathrm{b}},[12]^{\mathrm{c}}$, and $[30]^{\mathrm{d}}$.

components were from the succulent variety nor chemically characterized. Similar studies report mild anti-inflammatory activity of Physalis peruviana and Curcuma longa extracts over a rabbit pterygium model and cultured pterygium keratinocytes, respectively $[19,20]$. The inhibition of pterygium keratinocytes in the mentioned study was related to an increase in apoptotic activity. In our study, VEGF and CTFG expression changes were assessed. VEGF is an 
angiogenic cytokine with a pivotal role in normal and pathological angiogenesis and is upregulated in pterygium after UV radiation [21]. CTGF promotes connective tissue remodeling, thus activating tissue migration in pterygium [22]. Although the expression of these molecules has been reported as possible therapeutic targets, there is a lack of studies showing the effect of herbal extract treatment on these cytokines in pterygium. In our study, the expression of VEGF and CTGF was decreased after $S$. dendroideum treatment. This effect was not seen in healthy dermal fibroblasts. Recent studies report the arrest in pterygium proliferation with a decrease of VEGF using 5-fluorouracil $(5 \mathrm{FU})$ injection, an antifibrotic agent that inhibits the synthesis of DNA $[23,24]$. However, this treatment may produce hyperemia, keratitis, and pain and will not be entirely effective in preventing recurrence [25]. Further studies are needed to analyze the ability of $S$. dendroideum components to decrease VEGF and other pterygium cytokines with no side effects. The combination of the phytochemical compounds found in $S$. dendroideum could help in exerting beneficial activity without unwanted secondary effects. S. dendroideum had higher antioxidant activity (384.49 mM Trolox equivalents $/ \mathrm{mL}$ ) and total phenolic content $(33.67 \mathrm{mg}$ gallic acid equivalents (GAE)/g) than other plants in the Crassulaceae family, including Umbilicus intermedius, Umbilicus rupestris, and Sedum sempervivoides [26]. S. dendroideum phenolic content is within the average of that reported in other Sedum species, such as S. maximum and S. acre $[27,28]$. The compound profile found by HPLC analysis is consistent with previous reports, in which kaempferol glycosides have been identified as the most abundant compounds in $S$. dendroideum leaf juice and freeze-dried leaves $[2,11,29]$. The analysis of $S$. dendroideum freeze-dried leaves also showed the presence of myricetin and quercetin glycosides [2]. Furthermore, kaempferol, myricetin, and quercetin glycosides have been reported in species from the Crassulaceae family [30-35]. Myricetin, quercetin, and kaempferol aglycone from $S$. dendroideum have been linked to antioxidant, anti-inflammatory, antinociceptive, and gastroprotective activity $[1,2,4,11]$.

\section{Conclusions}

S. dendroideum is a plant well known for its healing properties in traditional medicine. In the ophthalmological area, there is a need for the pharmacological treatment of diseases of the ocular surface, such as pterygium. $S$. dendroideum showed activity in the decrease of the proliferation of HPF and the expression of VEGF and CTGF. The phenolic compound concentration, antioxidant activity, and phytochemical profile may play a role in these effects. These results set the baseline for further studies in vivo to test the preventive or therapeutic activity of S. dendroideum.

\section{Data Availability}

The data used to support the findings of this study are available from the corresponding author upon request.

\section{Conflicts of Interest}

The authors declare no conflicts of interest.

\section{References}

[1] V. Carrasco, L. A. Pinto, K. W. Cordeiro, C. A. L. Cardoso, and K. C. Freitas, "Freitas Antiulcer activities of the hydroethanolic extract of Sedum dendroideum Moc et Sesse ex DC. (balsam)," Journal of Ethnopharmacology, vol. 158, pp. 345351, 2014.

[2] B. B. Da Luz, A. F. De Oliveira, D. M. Ferreira, J. L. Dllazen, L. M. Cipriani De Souza, and M. F. Werner, "Chemical composition, antioxidant and gastrointestinal properties of Sedum dendroideum Moc \& Sesse ex DC leaves tea infusion," Journal of Ethnopharmacology, vol. 231, pp. 141-151, 2019.

[3] D. Da Silva, L. M. Casanova, M. C. Marcondes et al., "Antidiabetic activity of Sedum dendroideum: metabolic enzymes as putative targets for the bioactive flavonoid kaempferitrin," IUBMB Life, vol. 66, pp. 361-370, 2014.

[4] A. F. De Oliveira, G. E. D. Nascimento, M. Iacomini, L. M. C. Cordeiro, and T. R. Cipriani, "Chemical structure and anti-inflammatory effect of polysaccharides obtained from infusion of Sedum dendroideum leaves," International Journal of Biologicla Macromolecules, vol. 105, pp. 940-946, 2017.

[5] W. K. Chu, H. L. Choi, A. K. Bhat, and V. Jhanji, "Pterygium: new insights," Eye, vol. 34, pp. 1047-1050, 2020.

[6] A. Modenese and F. Gobba, "Occupational exposure to solar radiation at different latitudes and pterygium: a systematic review of the last 10 Years of scientific literature," International Journal of Environmental Research and Public Health, vol. 15, p. 37, 2017.

[7] R. Nuzzi and F. Tridico, "How to minimize pterygium recurrence rates: clinical perspectives," Clinical Ophthalmology, vol. 12, pp. 2347-2362, 2018.

[8] E. Cardenas-Cantu, J. Zavala, J. Valenzuela, and J. E. ValdezGarcia, "Molecular basis of pterygium development," Seminars in Ophthalmology, vol. 31, pp. 567-583, 2016.

[9] A. Ahmad and H. Ahsan, "Biomarkers of inflammation and oxidative stress in ophthalmic disorders," Journal of Immunoassay and Immunochemistry, vol. 11, pp. 1-15, 2020.

[10] E. Ortega-Hernández, V. Nair, J. Welti-Chanes, L. CisnerosZevallos, and D. A. Jacobo-Velázquez, "Wounding and UVB light synergistically induce the biosynthesis of phenolic compounds and ascorbic acid in red prickly pears (opuntia ficus-indica cv. Rojo vigor)," International Journal of Molecular Sciences, vol. 20, p. E5327, 2019.

[11] G. O. De Melo, D. C. Malvar, F. A. Vanderlinde et al., "Antinociceptive and anti-inflammatory kaempferol glycosides from Sedum dendroideum," Journal of Ethnopharmacology, vol. 124, pp. 228-232, 2009.

[12] J. Zavala, V. Trevino, A. A. Reyna-Fuentes et al., "Expresión de genes del metabolismo de lípidos y colesterol en fibroblastos de pterigión: análisis comparativo con adipocitos y otros fibroblastos," Revista Mexicana de Oftalmología, vol. 93, pp. 7-13, 2019.

[13] T. Estey, M. Cantore, P. A. Weston, J. F. Carpenter, J. M. Petrash, and V. Vasiliou, "Mechanisms involved in the protection of UV-induced protein inactivation by the corneal crystallin ALDH3A1," Journal of Biological Chemistry, vol. 282, pp. 4382-4392, 2007.

[14] S. Klebe, T. Callahan, and J. H. Power, "Peroxiredoxin I and II in human eyes: cellular distribution and association with 
pterygium and DNA damage," Journal of Histochemistry and Cytochemistry, vol. 62, pp. 85-96, 2014.

[15] C. J. Jaworski, M. Aryankalayil-John, M. M. Campos et al., "Expression analysis of human pterygium shows a predominance of conjunctival and limbal markers and genes associated with cell migration," Molecular Vision, vol. 15, pp. 2421-2434, 2009.

[16] T. H. Kang, H. O. Pae, J. C. Yoo, N. Y. Kim, G. I. Ko, and H. T. Chung, "Antiproliferative effects of alkaloids from Sedum sarmentosum on murine and human hepatoma cell lines," Journal of Ethnopharmacology, vol. 70, pp. 177-182, 2000.

[17] Y. Bai, B. Chen, W. Hong, Y. Liang, M. Zhou, and L. Zhou, "Sedum sarmentosum Bunge extract induces apoptosis and inhibits proliferation in pancreatic cancer cells via the hedgehog signaling pathway," Oncology Reports, vol. 35, pp. 2775-2784, 2016.

[18] N. R. Biswas, S. K. Gupta, G. K. Das et al., "Evaluation of Ophthacare ${ }^{\circledR}$ eye drops-a herbal formulation in the management of various ophthalmic disorders," Phytotherapy Research, vol. 15, pp. 618-620, 2001.

[19] S. Sancilio, S. Di Staso, S. Sebastiani et al., "Curcuma longa is able to induce apoptotic cell death of pterygium-derived human keratinocytes," BioMed Research International, vol. 2017, Article ID 2956597, 9 pages, 2017.

[20] J. M. Pardo, M. R. Fontanilla, L. F. Ospina, and L. Espinosa, "Determining the pharmacological activity of Physalis peruviana fruit juice on rabbit eyes and fibroblast primary cultures," Investigative Ophthalmology \& Visual Science, vol. 49, pp. 3074-3079, 2008.

[21] C. Livezeanu, M. M. Craitoiu, R. Manescu, C. Mocanu, and S. Craitoiu, "Angiogenesis in the pathogenesis of pterygium," Romanian Journal of Morphology and Embryology, vol. 52, pp. 837-844, 2011.

[22] G. Van Setten, M. Aspiotis, T. D. Blalock, G. Grotendorst, and G. Schultz, "Connective tissue growth factor in pterygium: simultaneous presence with vascular endothelial growth factor-possible contributing factor to conjunctival scarring," Graefes Archive for Clinical and Experimental Ophthalmology, vol. 241, pp. 135-139, 2003.

[23] N. Ghoz, J. Britton, A. R. Ross et al., "Management of primary pterygium with intra-lesional injection of 5 flurouracil and bevacizumab (Avastin)," Eye, vol. 33, pp. 1776-1783, 2019.

[24] M. S. Khan, S. Malik, and I. Basit, "Effect of intralesional 5 fluorouracil injection in primary pterygium," Pakistan Journal of Medical Sciences, vol. 32, pp. 130-133, 2016.

[25] C. Akarsu, P. Taner, and A. Ergin, "5-Fluorouracil as chemoadjuvant for primary pterygium surgery: preliminary report," Cornea, vol. 22, pp. 522-526, 2003.

[26] F. Q. Alali, K. Tawaha, T. El-Elimat et al., "Antioxidant activity and total phenolic content of aqueous and methanolic extracts of Jordanian plants: an ICBG project," Natural Product Research, vol. 21, pp. 1121-1131, 2007.

[27] K. Szewczyk, H. D. Smolarz, and U. Gawlik-Dziki, "Antioxidant properties of three species from Crassulaceae family," International Journal of Pharmacy and Pharmaceutical Sciences, vol. 4, pp. 107-108, 2012.

[28] A. Mavi, Z. Terzi, E. Ozgen, A. Yildrim, and M. Coskun, "Antioxidant properties of some medicinal plants: prangos ferulacea (apiaceae), Sedum sempervivoides (crassulaceae), malva neglecta (malvaceae), cruciata taurica (rubiaceae), rosa pimpinellifolia (rosaceae), galium verum subsp. verum (rubiaceae), urtica dioica (urticaceae)," Biological and Pharmaceutical Bulletin, vol. 27, pp. 702-705, 2004.
[29] G. O. De Melo, D. C. Malvar, F. A. Vanderlinde et al., "Phytochemical and pharmacological study of Sedum dendroideum leaf juice," Journal of Ethnopharmacology, vol. 102, pp. 217-220, 2005.

[30] N. Mulinacci, F. F. Vincieri, A. Baldi, M. Bambagiotti-Alberti, A. Sendl, and H. Wagner, "Flavonol glycosides from Sedum telephium subspecies Maximum leaves," Phytochemistry, vol. 38, pp. 531-533, 1995.

[31] D. Stojković, L. Barros, J. Petrović et al., "Ethnopharmacological uses of Sempervivum tectorum L. in southern Serbia: scientific confirmation for the use against otitis linked bacteria," Journal of Ethnopharmacology, vol. 176, pp. 297-304, 2015.

[32] A. Alberti, B. Blazics, and A. Kery, "Evaluation of Sempervivum tectorum L. Flavonoids by LC and LC-MS," Chromatographia, vol. 68, pp. 107-111, 2008.

[33] A. Uzun, A. Dalar, and I. Konczak, "Sempervivum davisii: phytochemical composition, antioxidant and lipase-inhibitory activities," Pharmaceutical Biology, vol. 55, pp. 532-540, 2017.

[34] I. Karabegovic Stanisavljevic, S. Stojičević, D. Velickovic, N. Nikolic, and M. Lazic, "Direct ultrasound-assisted extraction and characterization of phenolic compounds from fresh houseleek (Sempervivum marmoreum L.) leaves," Hemijska Industrija, vol. 72, p. 17, 2017.

[35] A. Alberti, S. Beni, E. Lacko, P. Riba, M. Al-Khrasani, and A. Kery, "Characterization of phenolic compounds and antinociceptive activity of Sempervivum tectorum L. leaf juice," Journal of Pharmaceutical and Biomedical Analysis, vol. 70, pp. 143-150, 2012. 